\title{
EXPERIMENTAL AND MATHEMATICAL INVESTIGATIONS ON UNCONFINED COMPRESSIVE BEHAVIOUR OF COSTAL SOFT SOIL UNDER COMPLICATED FREEZING PROCESSES
}

\author{
Wei Wang ${ }^{1}$ \\ $\mathrm{Na} \mathrm{Li}{ }^{1}$ \\ Fang Zhang ${ }^{1}$ \\ Aizhao Zhou ${ }^{2}$ \\ Snow $\mathrm{Chi}^{3}$ \\ ${ }^{1}$ School of Civil Engineering, Shaoxing University, Shaoxing, China \\ ${ }^{2}$ School of architectural and Civil Engineering, Jiangsu University of Science and Technology, Zhenjiang, China \\ ${ }^{3}$ Melbourne School of Design, Melbourne University, Victoria, Australia
}

\begin{abstract}
In order to properly understand the effect of freezing-thawing circle (FTC) to mechanical behavior of costal soft soil (CSS), unconfined compressive test is conducted. Six kind FTC times are designed from zero to five. The tested data show that: (1) unconfined compressive strength of CCS decreases nonlinearly with more FTC, and the strength after five FTC times becomes about 22\% of its original strength without any freezing-thawing experience; (2) stressstrain curves of all unconfined compressive samples can be well fitted by three-parameter hyperbolic model; (3) and relationship between two parameters and FTC times can be fitted by exponent function, while another parameter can be considered as 0.95. Consequently, one composite hyperbolic-exponent empirical formula is established in order to describe freezing-thawing-dependent stress-strain behavior of CSS. Finally, good agreements have been found between tested dada and simulated results.
\end{abstract}

Keywords: costal soft soil, stress-strain curve model, unconfined compressive behavior, freezing-thawing circle

\section{INTRODUCTION}

This paper is aimed at well understanding the freezingthawing-dependent unconfined compressive behavior by laboratory test and establishing an empirical formula to simulate unconfined compressive stress-strain curves of CSS.

Unconfined compressive behavior of soil is one basic subject to geotechnical engineering. Lots of effort has been devoted to it considering different kind soil. The work team of Liu ${ }^{1}$ conducted the assessment of unconfined compressive strength of cement stabilized marine clay. Effect of suction on unconfined compressive strength in partly saturated soils was discussed ${ }^{2}$ and the unconfined compressive strength of compacted granular soils by using inference systems was discussed $^{3,4}$. In some case, soil foundation or slope may experience freezing-thawing circle (FTC) process due to nature season change, day and night temperature difference, or artificial freezing engineering, which would make big difference to unconfined compressive strength of soil ${ }^{5,6}$.
People should properly understand this difference before corresponding engineering construction in order to assure its work function and engineering safety. Research work on the soil slope stability based on soil strength deterioration in seasonal frozen areas was made by $\mathrm{Ge}^{7}$. Experiment study on unconfined compressive strength before and after thaw of the forth layer silt clay in shanghai was presented by the work team of Song ${ }^{8}$. As to saturated silty clay, its hear strength properties influenced by freeze-thaw was put forward ${ }^{9}$. Wang ${ }^{10}$ conducted the testing study of freezing-thawing strength of unsaturated undisturbed loess considering influence of moisture content. Freezing-thawing behavior of fine-grained soils reinforced with polypropylene fibers was presented by Zaimoglu ${ }^{11}$. Now, some attention had been paid to the effect of freezing-thawing cycles on performance of fly ash stabilized expansive soil ${ }^{12}$. Although lots of work had been done and many study paper had been presented, study work on coastal soft soil (CSS) is not too much. 


\section{EXPERIMENTAL PART AND METHODOLOGY}

Laboratory test soil is CSS from Shaoxing Ctiy, China. It is grey color and with $30 \%$ moisture content. In order to study freezing-thawing-dependent unconfined compressive behavior, this test consist three main steps.

First step is to prepare initial soil samples. According to Chinese laboratory test code, twelve column shape soil samples are made with $81.0 \mathrm{~mm}$ height and $39.1 \mathrm{~mm}$ diameter, where six is for designed unconfined compressive test and other six is for additional remedy and repeated test.

Second step is to carry out different freezing-thawing circles test. Freezing-thawing box in Shaoxing University is used to complete this work. For one FTC, its freezing temperature is designed as $-12^{\circ} \mathrm{C}$ and its thawing temperature is designed as $15^{\circ} \mathrm{C}$; both freezing time and thawing time are all 24 hours. As to above ten column shape samples, this step is conducted as following:

(1) Two samples should be taken out previously for unconfined compressive test without any FTC, and these samples are denoted as $\mathrm{s} 0$.

(2) The rest ten samples are put into the freezing-thawing box to experience first one 48 hours FTC, then another two samples should be taken out for designed unconfined compressive test, and these two samples are denoted as s1.

(3) As this way, samples with FTC from 2 to 5 can be archived denoted by s2, s3, s4 and s5 until all twelve samples are all used.

Third step is to choose the laboratory apparatus and determine its loading procedure. In this test, one unconfined compressive apparatus with no. DW-1 is used made by Shangyu Survey and Geotechnical Instrumentation Company. Axial loading of it is automatically conducted by axial displacement with $0.1 \mathrm{~mm} / \mathrm{s}$. Test of all samples is finished and ended with the same axial strain reaching $8 \%$.

According to loading procedure designed in above section, six series stress-strain data for different samples from s0 to s5 are obtained, shown as in Fig. 1, where $\mathrm{q}$ and $\varepsilon$ denote axial stress and axial strain, respectively.

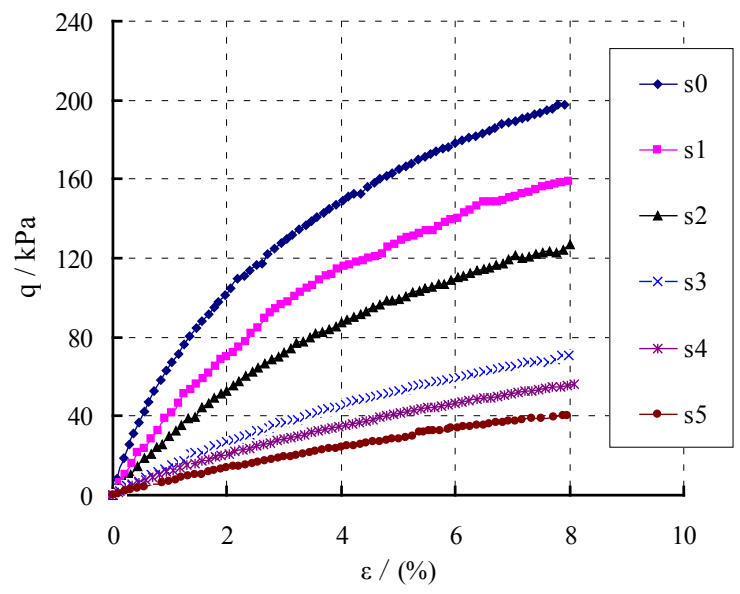

Fig. 1. Tested stress-strain data of different samples
From Fig. 1, unconfined compressive stress of all soil samples with various FTC and axial strain can be obtained, shown as in Table 1. It is evident that:

Tab. 1: Unconfined compressive stress with different FTC $/ \mathrm{kPa}$

\begin{tabular}{|c|c|c|c|c|c|}
\hline FTC & $\varepsilon=1 \%$ & $\varepsilon=2 \%$ & $\varepsilon=3 \%$ & $\varepsilon=5 \%$ & $\varepsilon=7 \%$ \\
\hline 0 & 67.5 & 101.2 & 129.8 & 164.5 & 189.7 \\
\hline 1 & 41.0 & 70.1 & 96.2 & 129.3 & 150.3 \\
\hline 2 & 30.0 & 52.7 & 72.1 & 99.5 & 121.2 \\
\hline 3 & 15.2 & 26.9 & 36.8 & 53.0 & 65.0 \\
\hline 4 & 10.2 & 21.1 & 28.3 & 41.4 & 51.2 \\
\hline 5 & 7.1 & 13.6 & 19.2 & 28.7 & 37.3 \\
\hline
\end{tabular}

(1) Whatever the FTC might be, the unconfined compressive stress increase nonlinearly with its increasing axial strain. For example, it increases from $67.5 \mathrm{kPa}$ when $\varepsilon=1 \%$ to 189.7 $\mathrm{kPa}$ when $\varepsilon=7 \%$ with $\mathrm{FTC}=0$.

(2) If axial strain is fixed, unconfined compressive stress decreases drastically with increasing FTC. For example, it changes from $164.5 \mathrm{kPa}$ to $28.7 \mathrm{kPa}$ with $\varepsilon=5 \%$.

In order to describe the FTC effect on unconfined compressive stress, normalized stress factor $\mathrm{K}$ is employed to express it:

$$
K=\frac{q_{\mathrm{i}}}{q_{0}} \times 100 \%
$$

Wherein, $\mathrm{q}_{\mathrm{i}}$ denotes the compressive stress with $\mathrm{FTC}=\mathrm{i}$ and $\mathrm{i}=0,1, \ldots, 5 ; \mathrm{q}_{0}$ denotes the compressive stress with $\mathrm{FTC}=0$, namely it denotes the compressive stress of sample without any FTC process.

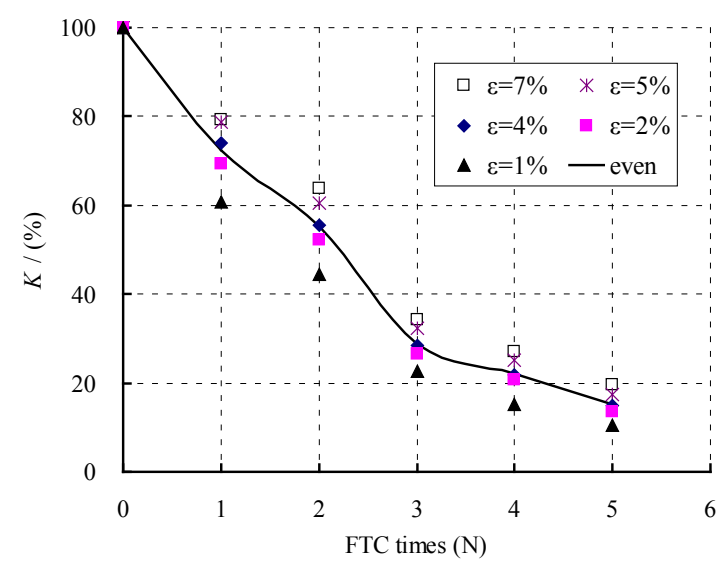

Fig. 2. Normalized stress factor K of different samples

Normalized stress factors of all samples and their even values are list in Fig. 2. From this figure, following conclusions can be drawn:

(1) If FTC is fixed, normalized stress factor K is not sensitive to axial strain $\varepsilon$. So, $\mathrm{K}$ can denote basic change law of the unconfined compressive strength of CSS, because it has nothing to do with axial strain which is selected to decide unconfined compressive strength.

(2) Normalized stress factor K becomes smaller and smaller 
with increasing FTC. Even values of $\mathrm{K}$ with FTC from 0 to 5 are $100 \%, 72 \%, 55 \%, 29 \%, 22 \%, 15 \%$, respectively.

(3) Differences between two close even values of K are $28 \%$, $17 \%, 23 \%, 7 \%, 7 \%$. It is to say, the sensitive area of FTC for unconfined compressive strength is from 0 to 3; after four FTC times, the change of unconfined compressive strength of CSS can be neglected to some degree.

\section{RESULTS AND DISCUSSION}

It is shown from Fig. 1 that, no mater what FTC is, the stress-strain curve of CSS consistently appear same shape to two-parameter hyperbolic model ${ }^{13}$, so it can be empirically written as:

$$
q=\frac{A \varepsilon}{B+\varepsilon}
$$

After using Eq. 2 to fit or describe investigated stressstrain data, many researchers have found the inferior of twoparameter hyperbolic model ${ }^{14}$. In order to improve the twoparameter hyperbolic model, we propose following formula to describe the stress-strain curve:

$$
q=\frac{A \varepsilon^{k}}{B+\varepsilon^{k}}
$$

In Eq. 2 and Eq. 3, A, B and $k$ are three undetermined soil parameters. Because of having three parameters, Eq. 3 is called as three-parameter hyperbolic model in following discussion. There is no denying the fact that three-parameter hyperbolic model is superior to two-parameter hyperbolic model.

After fitting the six stress-strain curves in the Fig.1 using Eq. 3, corresponding values of A, B and $k$ with various FTC can be archived and list as in Table 2 .

Tab. 2: Fitted values of the model parameters with various FTC

\begin{tabular}{|c|c|c|c|c|c|c|}
\hline $\mathrm{FTC}$ & 0 & 1 & 2 & 3 & 4 & 5 \\
\hline $\mathrm{A} / \mathrm{kPa}$ & 340.20 & 262.02 & 223.58 & 169.38 & 206.35 & 135.77 \\
\hline $\mathrm{B}$ & 4.18 & 5.37 & 6.41 & 10.34 & 15.21 & 17.70 \\
\hline $\mathrm{k}$ & 0.85 & 1.02 & 1.01 & 0.96 & 0.86 & 0.98 \\
\hline
\end{tabular}

Table 2 demonstrates that, with higher FTC times, values of parameter $A$ decrease monotonically but that of parameter $B$ exhibits a process of strict increasing. At the same time, FTC almost makes no difference to the value of parameter k, shown as in Fig. 3, so we can simply use average value 0.95 as the model parameter:

$$
k=g_{1}(N)=0.95
$$

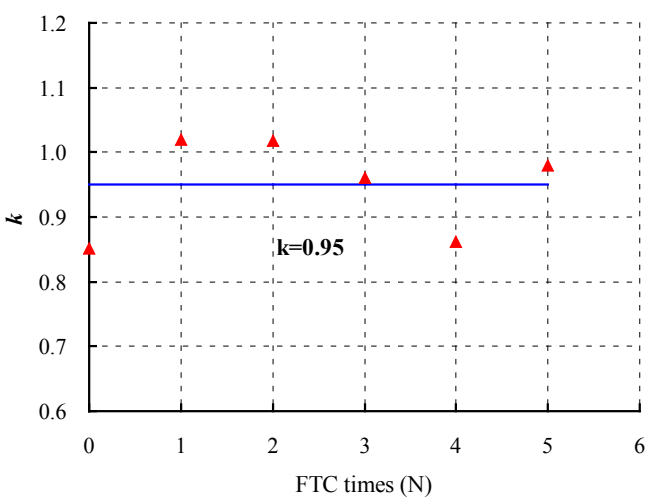

Fig. 3. Relationship between parameter $k$ and FTC

Two exponent functions are used to fit and build empirical expression for $\mathrm{A}$ and $\mathrm{B}$, and the best fitted empirical functions for them are negative and positive exponent functions, respectively. The fitted diagram are shown as Fig. 4 and Fig. 5 , and the empirical functions can be expressed as:

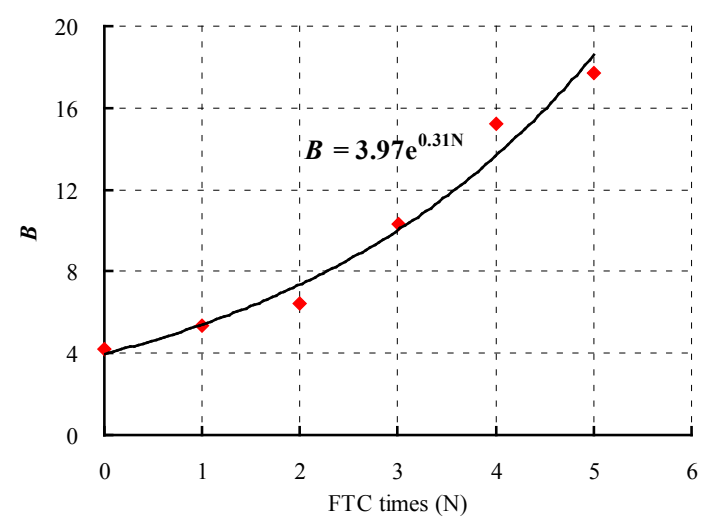

Fig. 4. Relationship between parameter A and FTC

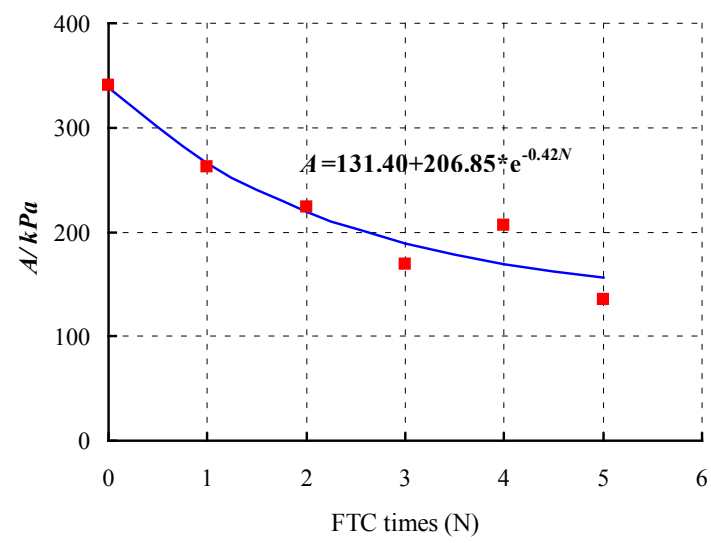

Fig. 5. Relationship between parameter B and FTC

$$
\begin{gathered}
A=g_{2}(N)=131.40+206.85 e^{-0.42 N} \\
B=g_{3}(N)=3.97 e^{0.31 N}
\end{gathered}
$$


Based on Eq. 3, Eq.4, Eq.5 and Eq. 6, empirical formula for CCS stress-strain curve considering different FTC times can be deduced as:

$q=\frac{A \varepsilon^{k}}{B+\varepsilon^{k}}=\frac{g_{2}(N) \varepsilon^{g_{1}(N)}}{g_{3}(N)+\varepsilon^{g_{1}(N)}}=\frac{\left(131.40+206.85 e^{-0.42 N}\right) \varepsilon^{0.95}}{3.97 e^{0.31 N}+\varepsilon^{0.95}}$

Eq. 7 can well describe the relationship among the axial stress, axial strain and FTC of CSS, and it is a three-parameter hyperbolic function with axial strain and a power function with FTC. So Eq. 7 can be considered as an empirical composite hyperbolic-exponent function formula (CHE formula).

Put $\mathrm{N}=0,1,2,3,4$ and 5 into Eq. 7, simulated stress-strain curve of CCS can be obtained and shown as in Fig. 6 .

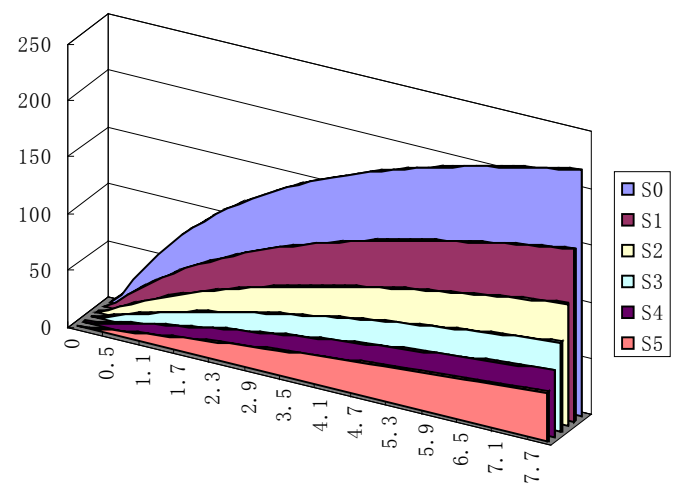

Fig. 6. Simulated stress-strain curve of CCS

In order to verify applicable ability of the presented CHP formula, comparisons between laboratory test and $\mathrm{CHE}$ formula simulating are conducted by taking s1 and s4 as example, and results are shown as Fig. 7.

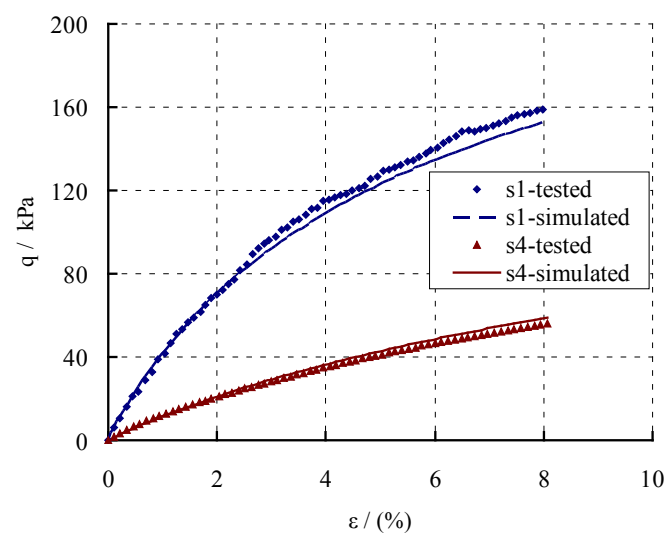

Fig. 7: Tested and simulated $q-\varepsilon$ curves

To further analyze the accuracy of CHE formula, the definition of the relative simulating error RD is presented:

$$
R D=\frac{q_{\text {test }}-q_{\text {simu. }}}{q_{\text {test }}} \times 100 \%
$$

Wherein: $\mathrm{q}_{\text {test }}$ represents the tested data and $\mathrm{q}_{\text {simu. }}$ represents the simulated data. The relative simulating errors of the $\mathrm{CHE}$ formula were calculated by equation (8), shown as in Fig. 8 .

Fig. 7 indicates that $\mathrm{CHE}$ formula can well simulate the tested stress-strain curves of s1 and s 4 samples. Fig. 8 indicates that relative simulating error of $\mathrm{CHE}$ formula is very small, especially, this error is just about $5 \%$ when $\varepsilon>1 \%$. According to Fig. 7 and Fig. 8, we can make conclusion that CHE formula can offer good agreements with the unconfined compressive stress-strain curves of CSS experienced various FTC times.

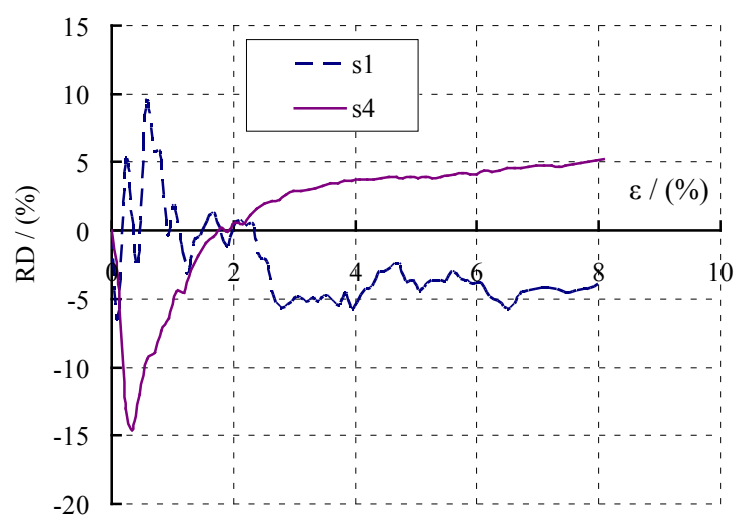

Fig. 8: Relative simulating error of $\mathrm{CHE}$ formula

Although above, following problems should be noted:

(1) Tested samples of this work are relatively small and not enough to express the general law of soil. In order to archive it, laboratory test on different kind soils should be conducted.

(2) Conclusions of this work are limited to present tested data and its mathematical analysis, micro-mechanical study considering FTC-dependent soil structural behavior should be further conducted by using scanning electron microscope.

(3) Although the empirical CHE formula can well simulate the tested stress-strain curves, its simulating error is bigger to some degree when $\varepsilon<1 \%$. It would be better for us to establish more precise formula based on more samples tests.

\section{CONCLUSIONS}

FTC effect on unconfined compressive behavior of CSS is studied in details, and basic work and conclusions are as fellows.

(1) Unconfined compressive stress decreases drastically with increasing FTC.

(2) Whatever the FTC might be, the unconfined compressive stress increase nonlinearly with its increasing axial strain. If FTC is fixed, normalized stress factor $\mathrm{K}$ is not sensitive to axial strain.

(3) Based on hyperbolic model, one three-parameter hyperbolic model and one empirical CHE formula are presented and proposed to describe the unconfined compressive $\mathrm{q}-\varepsilon$ curves with various FTC times. Good agreements have been found between $\mathrm{CHP}$ formula simulating and tested data. 


\section{ACKNOWLEDGMENTS}

The authors thank the reviewers who gave a through and careful reading to the original manuscript. Their comments are greatly appreciated and have help to improve the quality of this paper. This work is supported in part by the National Natural Science Foundation of China (NO. 41202222), and by the Ministry of Housing and Urban-Rural Development of China (NO. 2012-k3-4, NO. 2015-k3-020, NO. 2015-k4003). Some Laboratory tests were carried out by Li-sha Ma, Qiao-yuan Chi, Miao Li, Peng Jin and Yi-qi Tu.

\section{REFERENCES}

1. S. Y. LIU, D. W. ZHANG, Z. B. LIU: Assessment of unconfined compressive strength of cement stabilized marine clay. Marine Georesources and Geotechnology, 26, 19(2008).

2. J. CHAE, B. KIM, S. PARK, S. KATO: Effect of suction on unconfined compressive strength in partly saturated soils. KSCE Journal of Civil Engineering, 14(3), 281(2010).

3. E. KALKAN, S. AKBULUT, A. TORTUM, A. CELIK: Prediction of the unconfined compressive strength of compacted granular soils by using inference systems. Environ. Geol., 8, 1429(2009).

4. X. Q. CHEN, C. H. LI, W. WANG, X. ZHANG: Active geotechnical treatment technology for permafrost embankment of Qinghai-Tibet railway. The Electronic Journal of Geotechnical Engineering, 17(Y), 3635(2012).

5. Y. FENG, J. L. HE, L. LIANG: Experimental study of the shear strength characteristics of fine-grained soil under freezing and thawing cycles. Journal of Glaciology and Geocryology, 30(6): 1013(2008).

6. Z. Q. ZHANG, Z. P. HU, J. ZHAO: Strength properties of lime-fly ash loess under freezing-thawing cycles. Journal of Traffic and Transportation Engineering, 11(6): 24(2011).

7. Q. Ge, H. Wu, Y. F. Gong: Research on the soil slope stability based on soil strength deterioration in seasonal frozen areas. Advanced Materials Research, 243: 4270(2011).

8. Z. G. SONG, Y. Q. TANG, J. HONG: Experiment study on unconfined compressive strength before and after thaw of the forth layer silt clay in shanghai. Low Temperature Architecture Technology, 31(12): 85(2009).

9. L. L. YU, X. Y. XU, M. Q. LI, P. F. LI, Z. L. YAN: Influence of freeze-thaw on shear strength properties of saturated silty clay. Rock and Soil Mechanics, 31(8): 2448(2010).

10. T. H. WANG, S. F. LUO, X. J. LIU. Testing study of freezing-thawing strength of unsaturated undisturbed loess considering influence of moisture content. Rock and Soil Mechanics, 31(8): 2378(2010).

11. ZAIMOGLU A. SAHINL. Freezing-thawing behavior of fine-grained soils reinforced with polypropylene fibers. Cold Regions Science and Technology, 60(1): 63(2010).

12. BIN-SHAFIQUE SAZZAD, RAHMAN, K., AZFAR IREEN: The effect of freezing-thawing cycles on performance of fly ash stabilized expansive soil subbases. Geotechnical Special Publication, 211: 697(2011).

13. J. J. GUO, W. WANG, X. N. WANG: Improved hyperbolic model for harden/soften stress-strain curve of Yangtze River soil. The Electronic Journal of Geotechnical Engineering, 17(L): 1675(2012).

14. W. WANG, X. J. SONG, H. LING, T. H. LU, G. W. ZHOU: Composite exponential-hyperbolic model for stress-strain curve of seashore soft soil. Chinese Journal of Geotechnical Engineering, 32(9): 1455(2010).

\section{CONTACT WITH THE AUTHOR}

Wei Wang

e-mail:wangwells@qq.com

School of Civil Engineering

Shaoxing University

Shaoxing

CHINA 